Article

\title{
What Drives Green Innovation? A Game Theoretic Analysis of Government Subsidy and Cooperation Contract
}

\author{
Weimin Ma, Ranran Zhang * and Shiwei Chai \\ School of Economics and Management, Tongji University, Shanghai 200092, China; mawm@tongji.edu.cn (W.M.); \\ csw@tongji.edu.cn (S.C.) \\ * Correspondence: zhangranran@tongji.edu.cn
}

Received: 23 August 2019; Accepted: 4 October 2019; Published: 10 October 2019

check for updates

\begin{abstract}
Green innovation, implemented by enterprises, contributes to sustainable development and environmental protection. However, because of the high cost and high risk of green innovation, enterprises are reluctant to step into green innovation activities in practice. Government subsidies are conducive to promoting green innovation in enterprises. To investigate firms' preferences for green innovation, we consider a three-player game in a supply chain where a government offers subsidies (price, innovation, or both subsidies) to a manufacturer and a retailer, while the latter two players cooperate with each other through contracts (revenue-sharing and cost-sharing contracts). By exploring the impacts of government subsidies and cooperative contracts on the optimal level of green innovation efforts and profits of participants, we find that: (1) for green innovation that leads to increased production costs, the government should subsidize both the retailer and the manufacturer to improve the level of green innovation; (2) the revenue-sharing contract is more effective than the cost-sharing contract under the premise of government subsidies; and (3) the revenue-sharing ratio decreases in production and innovation costs, while the cost-sharing ratio increases in these two costs.
\end{abstract}

Keywords: cost-sharing contract; game theory; government subsidy; green innovation effort; revenue-sharing contract

\section{Introduction}

Consumers, governments and the media are putting increasing pressure on environmental protection and energy conservation, which has prompted enterprises around the world to step into "green" scenes to maintain a competitive edge and improve environmental quality [1-3]. Green product innovation has long been a key avenue for revenue and profit growth [2] and mitigating environmental impact [4] in certain sectors (e.g., Philips uses green marketing for "Marathon" and product sales have increased by $12 \%$, saving $\$ 26$ per unit of energy cost over its five-year lifetime [5]). Many companies have rapidly incorporated green concepts into their product innovation plans [6]. IKEA, for example, emphasizes environmental protection and sustainability in its production process [7]; H\&M and Levis are using new technologies to reduce carbon emissions in manufacturing [8]. Despite these validating examples, many companies still face the problem of how to effectively invest in green innovation to increase the greenness of their products [5].

Green innovation refers to technological innovations related to energy conservation, pollution prevention, waste recycling and green product design, which differs from traditional innovation [9]. Green innovation investments are characterized by high costs and high risks [10]. Therefore, the motivation for innovation in a company is not always sufficient. Governments around the world are encouraging firms to promote sustainability (e.g., Europe, the United States, Canada, and China) [11]. 
There are various forms of government incentives [12], among which the most common is government subsidies, and price subsidies and innovation efforts subsidies are the most common forms of subsidies [13]. In addition, governments can jointly provide price subsidies and innovation subsidies to stimulate green innovation in practice. This paper takes government subsidies as the research object, aiming to better understand the role of government incentives in the green innovation of enterprises.

Cooperation between supply chain partners plays a crucial role in the success of a sustainable supply chain $[5,14]$. Firms are not only tweaking their own business operations, dabbling in green concepts to reduce their business footprint, but also rebuilding their relationships with partners [3]. Many multinational automobile companies (such as Mercedes-Benz in 1987, GM in 1997, and Toyota in 2000) have established R\&D partnerships with Chinese partners [15]. Revenue-sharing contracts [16-18] and cost-sharing contracts $[19,20]$ are effective mechanisms to promote cooperation among supply chain members [21]. Revenue-sharing contracts imply that a retailer pays a manufacturer the wholesale price of each purchase, plus a percentage of the retailer's revenue [22]. For example, a buy-back contract is a special case of revenue-sharing contracts in the newsvendor situation [23]. A cost-sharing contract is a common form of cooperation in the case of uncertain manufacturing costs. In particular, in the energy and manufacturing industries, the trend of energy conservation, emission reduction and cost sharing is prominent [24]. Therefore, it is an inevitable trend for upstream enterprises to cooperate with downstream firms to achieve energy conservation, emission reduction and environmental protection through cooperation contracts [25]. The main purpose of this paper is to explore which cooperative contract is the best one to promote green innovation activities under government subsidies.

The aforementioned practices show that enterprises around the world are increasingly adopting green innovation initiatives to meet the demand of environmentally conscious consumers for sustainable products. In fact, green innovation strategies have always been a key way to increase revenue and profit, reduce costs, and mitigate environmental impacts. Due to the high risks and costs of green $R \& D$, it is impossible for any firm alone to take green innovation initiatives. Government incentives and cooperative contracts are an effective way to address this challenge. However, although government incentives and cooperative contracts are critical to the sustainable development of this emerging practice of green innovation strategies, the existing literature pays little attention to the combined impact of government incentive schemes and cooperative contracts on optimal pricing and green innovation efforts. Even though some literature [4,26,27] discusses the impact of government subsidies on green innovation strategies and shows that government subsidies can promote the development of green innovation, most of the research in this area is based on the assumption that government subsidies are an exogenous constant. Few studies have endogenized government subsidies into green innovation decisions or have considered the best effect of green policies from the perspective of whom the government should subsidize. In addition, in terms of the role of cooperative contracts in green innovation, some studies $[15,20,25,28]$ have explored the impact of cooperative contracts on the greenness of products. However, few papers consider which kind of cooperative contracts are more conducive to green innovation activities under the premise of government subsidies, and even fewer consider the impact of government subsidies on the choice of contracts. This paper fills these gaps in the literature by addressing the following research questions:

- Who should the government subsidize (the retailer, the manufacturer or both) to achieve the best green innovation when government subsidies are endogenized into green decision-making?

- What are the effects of different subsidy schemes on green innovation effort decisions, optimal pricing and profit distribution among supply chain partners?

- What kind of cooperation contract should the retailer and the manufacturer choose on the premise of government subsidies?

- How does the government subsidy policy affect the cost/revenue sharing-ratio of cooperation contracts? 
To answer these questions, we consider a three-player game in which a government, a manufacturer, and a retailer make decisions to maximize their own interests in a supply chain. The government aims to promote the development of green innovation and improve social and environmental welfare by subsidizing the retailer or the manufacturer. An environmentally responsible manufacturer invests in green innovation activities to produce green products to meet the needs of green-conscious consumers [5]. The manufacturer who maximizes profits determines the level of green innovation efforts through a trade-off between product sales revenue and innovation investment costs. The retailer purchases green products from the manufacturer and sells them to consumers. First, to investigate the impact of government subsidies on green innovation, we endogenize government subsidies into green innovation decisions in the following three cases: price subsidies for retailers, innovation subsidies for manufacturers, and simultaneous subsidies for both. Furthermore, we compare the equilibrium values of green efforts in the corresponding subsidy schemes. Through this comparison, we can clearly know which subsidy scheme is the best way to promote green innovation. After receiving government subsidies, the retailer and the manufacturer can work together to achieve green innovation through contracts. The decision-making of the manufacturer and the retailer under revenue-sharing and cost-sharing contracts are analyzed, respectively. In addition, by comparing the level of green efforts and the profits of the retailer and the manufacturer in the corresponding cooperation contracts, we can better understand which kind of contract is the best choice to promote supply chain cooperation under the premise of government subsidies. To illustrate the logical structure of this study, the model framework is shown in Figure 1. First, we study how the government determines the optimal subsidy scheme, and then, on the premise of the optimal subsidy scheme, we explore how to select the best cooperation contract for supply chain partners.

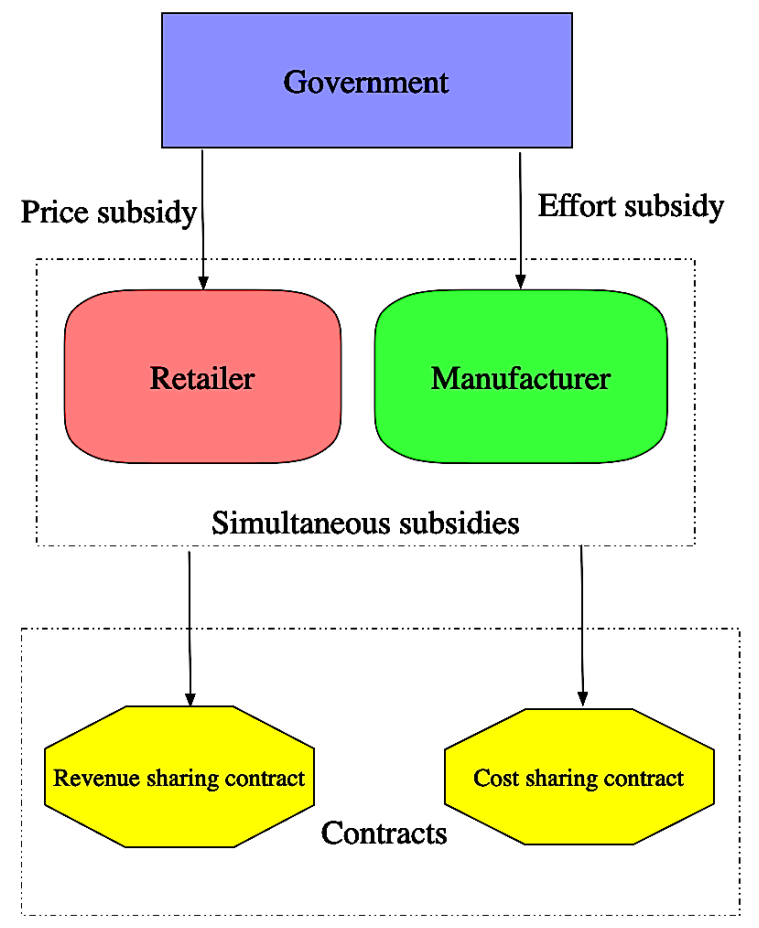

Figure 1. Model framework.

We briefly summarize the key findings. First, for the green innovation initiatives that lead to increased production costs, the government's scheme of subsidizing the retailer and the manufacturer simultaneously can achieve the best results of green innovation efforts. A counter-intuitive but interesting result is that the level of green efforts under the green innovation subsidy scheme is always lower than the level under the green product price subsidy scheme. Second, 
the revenue-sharing contract is more effective than the cost-sharing contract under the premise of government subsidies. The level of green innovation efforts as well as the profits of the manufacturer and the retailer under the revenue-sharing contract are higher than those under the cost-sharing contract. Therefore, the revenue-sharing contract can help the manufacturer and the retailer achieve a win-win situation in green innovation. Third, production costs and innovation costs have different effects on the revenue-sharing rate and cost-sharing rate. As these two costs increase, the revenue sharing rate decreases, while the cost sharing rate increases.

Our research contributes to the literature on green supply chains by jointly investigating the impact of government subsidy schemes and cooperative contracts on green innovation efforts. In the operational management literature, government incentives and cooperation contracts are widely recognized as key measures to promote the development of green innovation. To the best of our knowledge, this is the first attempt to incorporate three government subsidy schemes (subsidies for the retailer, the manufacturer, or both) and two types of cooperative contracts (revenue-sharing and cost-sharing contracts) into green innovation models using game theoretical approach. In addition, this paper considers the important practical characteristics of green innovation efforts, that is, green innovation efforts will increase production costs, thereby affecting green decision-making, which fills the research gap of green innovation literature. It also addresses two of the four research gaps (i.e., largely neglected market forces and vertically aligned sustainable strategies) identified by Tang and Zhou [29]. Considering that consumers' environmental awareness plays an important role in the investment and management of corporate sustainability, we incorporate consumers' preferences for green innovation efforts into the demand function, which addresses the first research gap of the largely neglected market forces. Through the analysis of the cooperation between upstream manufacturers and downstream retailers under two different contracts, the second research gap of vertically aligned sustainable strategies is filled.

The research results have important managerial implications for both regulators and managers. For regulators, our study shows that it is a necessity to subsidize retailers and manufacturers at the same time to achieve the best policy effect of green innovation. For managers, our results suggest that under the optimal government subsidy scheme, the best choice for cooperation among supply chain members is the revenue-sharing contract. The revenue-sharing contract is superior to the cost sharing contract in terms of green innovation efforts and the profitability of supply chain members. These insights will help policymakers and business leaders find a win-win solution in the pursuit of sustainable development.

The rest of this paper is organized as follows. In Section 2, we review the relevant literature. In Section 3, we provide the prerequisites and assumptions. In Section 4, we build and analyze government subsidy models. In Section 5, we present and analyze cooperation contract models. We present numerical experiments in Section 6. We discuss and summarize the research in Sections 7 and 8, respectively. In addition, all the proofs are given in Appendix A.

\section{Literature Review}

This study relates to three streams of research: green supply chain management, governmental intervention in green supply chains, and supply chain coordination. We review the research related to each stream and highlight the differences between this study and the existing literature in the following subsections.

\subsection{Green Supply Chain Management}

The first stream of research is green supply chain management. Green supply chain management is receiving more and more attention from researchers who have incorporated environmental sound into supply chain management research [3,6,17,20,30-32]. Recent review papers present potential opportunities and research issues in green supply chains. For example, Srivastava [30] conducted a comprehensive and new research in the field of green supply chain 
management (GrSCM) and highlighted key research issues and opportunities using abundant existing literature. Fahimnia et al. [32] presented a thorough bibliometric and network analysis of green supply chain management to identify the current research interests and potential directions for future research. Green supply chains play a vital role in developing green products and preventing green pollution [26]. As we have observed, green supply chain management mainly focuses on green design [33], reverse logistics [34], and by-products from product use [14].

In recent years, scholars have established game models to quantitatively analyze the decisions of green supply chain members [25]. Considering consumers' sensitivity to green products, Ghosh and Shah [20] discussed the coordination of supply chains through game theory and show that greenness level of products are influenced by cost sharing contracts. Ghosh and Shah [35] developed game theoretic models and examined an apparel serial supply chain wherein participants initiate product "greening". Their findings suggest that cooperation between participants leads to higher levels of greenness and higher retail prices. Zhu and He [36] studied the green product design in supply chains under horizontal competition using a game-theoretic approach and found that the distortion from a non-coordinated supply chain has a counter-intuitive impact on the "greenness" of products. Hong and Guo [5] used game theory to study the impact of cooperative contracts on environmental performance and conclude that cooperation is not necessarily beneficial to all partners.

The literature discussed above mainly investigates the impact of green investment on product greenness and product pricing decisions under the assumption that green investment has no impact on product production costs. Our research is based on the assumption that green innovation efforts will lead to increased production costs and concentrates on how government subsidies and cooperative contracts affect the degree of green innovation efforts and the profits of supply chain members. The hypothesis of this study is more in line with the reality of green innovation and contributes to enriching the green innovation literature in green supply chain management.

\subsection{Governmental Intervention in Green Supply Chains}

The second related stream of research is governmental intervention in green supply chains. Governments often use incentive and deterrent policies to exert positive and negative external influences on enterprises [17,37-39]. However, in the early literature, the impact of government financial interventions on green supply chains was rarely considered [37]. In recent years, researchers have conducted quantitative research on the impact of government intervention on green supply chain decision-making. Mitra and Webster [4] established a two-stage model to examine the impact of government subsidies on remanufacturing activities and reveal that subsidies can promote remanufacturing activities. Xue et al. [26] examined the centralized and decentralized decision-making models of a green supply chain based on game theory and studied the impact of government subsidies on energy conservation. Their results show that government subsidies can significantly improve social welfare and improve the energy-saving level of products. Considering the externalities of consumption, Raz and Ovchinnikov [27] presented a stylized framework to consider three government intervention mechanisms (namely, joint mechanism using both subsidies and rebates and two simplified mechanisms using only rebates or only subsidies) for public interest goods. They found that the joint mechanism results in a negative subsidy (i.e., a tax) unless the externality is very small.

Different from prior studies that mostly focus on the hypothesis that government subsidies are exogenous and constant, our study endogenizes government subsidies into green innovation decision-making. The research of Chen et al. [13] is most relevant to our work in terms of edogenizing government subsidies and exploring the impact of government subsidies on sustainable innovation in the supply chain. In their research, they endogenized government subsidies into a research joint ventures (RJV) and consider the impacts of two forms of RJV formation (initiated by the retailer and the manufacturer) and two types of subsidies (per-unit production subsidy and innovation effort subsidy) on the level of innovation efforts. The important differences between our paper and their research lie in: (i) The object of government subsidy is different. Their main concern is how the government can 
fund a research joint venture to achieve the best policy outcomes. Our paper compares and analyzes who the government should subsidize (retailers, manufacturers or both) to achieve the best green efforts. (ii) The research order of government subsidies and cooperation contracts is different. In their models, government subsidies and revenue-sharing contracts are simultaneously included in the profit function. They only considered who dominates the power structure of the project and not the impact of government subsidies on the proportion of revenue distribution. However, in our model, we first identify the best government subsidy scheme. Then, the optimal government model is combined with a revenue-sharing contract and a cost-sharing contract, which are incorporated into the profit function of retailers and manufacturers, respectively. This paper analyzes the optimal cooperative contract and considers the impact of government subsidies on sharing ratios, which expands the research of Chen et al. [13] on government subsidies and cooperative contracts.

\subsection{Supply Chain Cooperation}

The third stream of research is supply chain cooperation. Cooperation between supply chain partners is achieved through cooperation mechanisms. The contract mechanism is an agreement among different companies regarding different trade parameters [40]. To improve the performance of the supply chain, it is necessary to establish appropriate mechanisms to coordinate a decentralized supply chain to enhance the relationship between partners [41]. Veugerlers [42] provided detailed reviews on horizontal R\&D cooperation between competitors. From a transaction cost perspective, Brockhoff [43] studied the R\&D cooperation between firms and shows that the perception of transaction costs is related to the perceived success of the cooperation. Given the uncertainty of developing and launching new products, Bhaskaran and Krishnan [2] examined the impact of arrangements, including not only revenue sharing but also development costs and work sharing between firms, and found that the investment and innovation sharing are related to products without pre-existing revenues and depend on the revenue sharing ratio among firms. These research mainly focuses on horizontal cooperation between firms.

More and more firms with "buyer-supplier" relationships are cooperating in R\&D activities [15]. A few papers have considered vertical innovation collaboration between upstream suppliers and downstream buyers. For example, Ge et al. [15] studied the R\&D cooperation behavior of enterprises in a supply chain, and their results show that, through cartelization, the two enterprises could achieve a win-win situation. Ghosh and Shah [20] explored the impact of two cost-sharing contracts (i.e., retailer-led cost-sharing contracts and bargaining cost-sharing contracts) on key decisions (i.e., product greening levels, prices, and profits) of a retailer and a manufacturer through game theory. Song and Gao [25] established a game model with two kinds of revenue-sharing contracts (i.e., retailer-led revenue-sharing contracts and bargaining revenue-sharing contracts) for cooperation between upstream and downstream members of a green supply chain, and quantitatively analyzed the impact of contracts on decision variables. Talluri et al. [28] proposed a set of optimization models in the single-manufacturer and multiple suppliers (SMMS) scenario and the two-manufacturer and multiple suppliers (TMMS) scenario to address how manufacturers allocate investments to improve their suppliers' capabilities. These studies reveal that cooperation can improve the performance of green supply chains.

However, most of the literature in this area focuses on the impact of inter-firm cooperation on the greenness level of products and lacks the consideration of the impact of government subsidy schemes on cooperation contracts. Our study contributes to the literature on green innovation initiatives in green supply chain by investigating the impact of government subsidies on the choice of cooperative contracts to examine the impact of government subsidies on green innovation efforts indirectly. Our research differs from the existing literature in that we incorporate the level of green innovation efforts into a demand function. By analyzing and comparing the results of the revenue-sharing contract and cost-sharing contract with this new demand function, we explore how 
the retailer and the manufacturer cooperate with each other to improve the level of green innovation under the premise of government subsidies.

In summary, this paper attempts to fill in the research gap of jointly examining the impact of government subsidies and cooperative contracts on decision-making of green innovation efforts by considering variable production costs in models, that is, green innovation efforts increase production costs. By comparing the impact of the three subsidy schemes and the two cooperative contracts on green innovation efforts, we are able to find the best subsidy scheme for the government and the optimal cooperative contract for supply chain partners to promote green innovation.

\section{Prerequisites and Assumptions}

We consider a two-echelon supply chain consisting of an upstream manufacturer and a downstream retailer. Under this structure, the manufacturer engages in green innovation efforts and bears the upfront costs of green innovation investments. However, the benefits from increased demand are shared by both the manufacturer and the retailer. The retailer sells products to consumers at retail prices. We make the following main assumptions:

Assumption 1. Both the manufacturer and retailer are risk neutral and aim to maximize their own profits [6,44]. The manufacturer is assumed to produce only one product, and the retailer is constrained to sell only one product [35].

Although the setting of Assumption 1 is considered simple, this assumption enables us to understand the effects of cooperation between the manufacturer and retailer in the green supply chain.

Assumption 2. According to the literature on green innovation $[13,19,45]$, consumers have higher utility purchasing green products with green innovation, so their willingness-to-pay increases, leading to an increase in market demand. We utilize a linear demand function, $D=1+e-p$, to capture the relationship among the market demand, price, and the green innovation effort, where $p$ is the retail price and $e$ is the level of green innovation efforts. Without loss of generality, we assume that the sensitivity coefficient of demand to green efforts is 1, similar to Chen et al. [13].

Clorox's natural cleaning products, for example, contain $50 \%$ or more natural solutions in their products and are so popular with consumers that demand for these cleaning products is much higher than that for other brands [46].

Assumption 3. Following Chen et al. [13], Arora and Ceccagnoli [47], and Atasu and Subramanian [48], we denote e as the level of efforts exerted for green innovation. The higher is the degree of green innovation efforts, the greater is the investment required for green innovation development. We assume that the green innovation effort e generates effort cost of $\kappa e^{2}$, where $\kappa>0$ represents the coefficient of the effort cost. The quadratic effort cost indicates a decreasing marginal return of green innovation efforts.

Green innovation efforts mainly refer to efforts to develop greener technologies, undertake research and development projects that can improve productivity, or invest in environmental programs. In addition, the phenomenon that rational manufacturers target "low-hanging fruit" first, so that further improvements in green innovation become increasingly difficult confirms the rationality of the quadratic effort cost assumption [49].

Assumption 4. According to Chen et al. [13], we assume that the green product innovation improves environmental performance but also increases the unit production cost, $C(e)=c_{0}+\beta e$. In the absence of green innovation efforts, the unit production cost is expressed as $c_{0}$. Without loss of generality, we normalize the base cost $c_{0}$ to zero. By investing e in green innovation efforts, the manufacturer will increase the production cost by $\beta$, where $\beta \in[0,1]$ is the coefficient of increase in unit production cost due to green innovation efforts. 
For example, sustainable coffee production is often accompanied by an increase in production costs. Introducing greener production materials and green innovative technologies into supply chains means increased labor input and increased unit production costs of coffee. Specifically, if the production process is more environmentally friendly, the cost of coffee production will increase by about 30\% [50].

Previous scholars have different assumptions about the impact of green innovation on production costs. Yenipazarli [3] assumed that green innovation can reduce production costs, while Chen et al. [13] supposed that production costs increase with green innovation efforts. This is mainly because they considered different types of green innovation. Green innovation can be divided into three categories: green product innovation, green process innovation, and green management innovation $[9,48,51,52]$. In general, green product innovation and green process innovation affect the production cost of products [53].

Green product innovation is usually an eco-efficient innovation that not only improves environmental performance but also reduces production costs. In the case of washing machines, a supplier invests in manufacturing practices of a washing machine to limit the usage of water and energy, thereby saving costs and reducing emissions. Green process innovation is a costly environmental innovation that increases production costs. Coffee, for example, would cost $30 \%$ more to produce if the process is more environmentally friendly [50]. However, there are relatively few studies on green process innovation, so our paper mainly considers green efforts in green process innovation, which increases the production cost of products. We summarize the relevant notations in Table 1.

Table 1. Notations.

\begin{tabular}{cl}
\hline Notations & \\
\hline$\kappa$ & The cost coefficient of green innovation efforts, $\kappa>0$ \\
$\psi$ & The marginal benefit in green innovation efforts to the government, $\psi>0$ \\
$\beta$ & The cost coefficient in unit production due to green innovation effort, $0<\beta<1$ \\
$p$ & Retail price \\
$w$ & Wholesale price \\
$e$ & Degree of green innovation effort \\
$\tau$ & Green product price subsidy \\
$g$ & Green innovation effort subsidy, $0<\mathrm{g}<\kappa$ \\
$\mathcal{c}$ & Per-unit production cost \\
$c_{0}$ & Basic production cost, normalized to zero without any efforts \\
$\pi_{r}$ & Retailer's profit \\
$\pi_{m}$ & Manufacturer's profit \\
$\pi_{g}$ & Government's utility \\
$\lambda_{1}$ & Revenue-sharing ratio \\
$\lambda_{2}$ & Cost-sharing ratio \\
$D$ & Demand function \\
$\Omega$ & Government's subsidy \\
\hline
\end{tabular}

Based on the above assumptions, the retailer's profit function can be obtained as follows:

$$
\max _{p} \pi_{r}=(p-w) D
$$

The manufacturer's profit function can be expressed as follows:

$$
\max _{w, e} \pi_{m}=(w-\beta e) D-\kappa e^{2} .
$$

\section{Government Subsidy Models}

In government subsidy models, the government first determines the subsidy mode (i.e., subsidies for the retailer, the manufacturer, or both). Then, the manufacturer sets wholesale prices and levels 
of green innovation efforts. The retailer sets retail prices based on decisions of the manufacturer and the government. The sequence of events is shown in Figure 2.

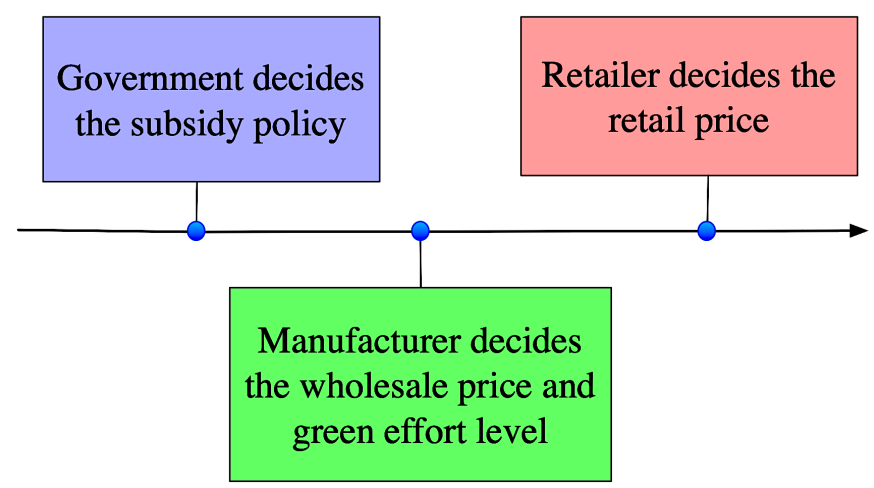

Figure 2. Sequence of events.

We consider three different government subsidy schemes: green product price subsidy (PS) for retailers, green innovation effort subsidy (IS) for manufacturers, and subsidies for both firms (BS). In each section, we focus on the impact of government subsidies on the manufacturer's green innovation efforts.

\subsection{Scenario 1: Green Product Price Subsidy for The Retailer}

In this case, the government provides price subsidies to the retailer to encourage sales of green products, thereby indirectly increasing the level of green innovation efforts of the manufacturer. The green product price subsidy depends on the demand of green products, i.e., $\Omega=\tau D$, where $\tau \geq 0$ is the unit price subsidy amount for per sales unit. Under the green product subsidy scheme, the profits of the retailer and the manufacturer are:

$$
\begin{gathered}
\max _{p} \pi_{r}=(p-w) D+\tau D, \\
\max _{w, e} \pi_{m}=(w-\beta e) D-\kappa e^{2} .
\end{gathered}
$$

According to Chen et al. [13], Raz and Ovchinnikov [27], and Krass et al. [54], we incorporate the positive externalities of green innovation efforts, subsidies, firms' profits, and consumer surplus into the government's profit function, which can be expressed as:

$$
\max _{g} \pi_{g}=\psi e-\tau D+\pi_{r}+\pi_{m}+D^{2} / 2
$$

The first term corresponds to external direct benefits of sustainable innovation efforts, where $e$ denotes the level of endogenous efforts and $\psi e$ represents the indispensable sustainable benefits. The second term is the price subsidy for the retailer. The third and fourth terms are the profits of the retailer and manufacturer, respectively, and the last term is consumer surplus.

The equilibrium decisions of the manufacturer and the government under the green product price subsidy is calculated using the backward method.

Proposition 1. Given $\kappa>(1-\beta)^{2} / 2$ and $0<\beta<1$, the level of green innovation efforts invested by the manufacturer and the unit green product price subsidy provided by the government in equilibrium are:

$$
\left\{e^{P S}, \tau^{P S}\right\}=\left\{\frac{A^{2} \psi+2 A \kappa}{4 \kappa^{2}-2 A^{2} \kappa}, \frac{12 \kappa^{2}-A\left(A^{2} \psi-8 \kappa \psi\right)}{4 \kappa^{2}-2 A^{2} \kappa}\right\}
$$


Proposition 1 presents the optimal level of green innovation efforts and unit green product price subsidy for the retailer. We can see that these two variables are functions of the unit production cost $(\beta)$, the green innovation effort cost $(\kappa)$, and the marginal benefit in effort levels to the government $(\psi)$.

Proof. Please see Appendix A.

\subsection{Green Innovation Effort Subsidy for The Manufacturer}

Under green innovation efforts subsidies, the government encourages green innovation by subsidizing the manufacturer to reduce the cost of green innovation. We assume that the green innovation subsidy is directly dependent on the level of green innovation efforts (i.e., $\Omega=g e^{2}$, where $0 \leq g \leq \kappa)$, similar to Chen et al. [13]. Under the green innovation effort subsidy, the profit function of the retailer, the manufacturer and the government are:

$$
\begin{gathered}
\max _{p} \pi_{r}=(p-w) D, \\
\max _{w, e} \pi_{m}=(w-\beta e) D-\kappa e^{2}+g e^{2}, \\
\max _{g} \pi_{g}=\psi e-g e^{2}+\pi_{r}+\pi_{m}+D^{2} / 2 .
\end{gathered}
$$

In Equation (8), the government subsidizes the manufacturer for green innovation efforts. We calculate the optimal level of green innovation efforts and the unit subsidy under the green innovation subsidy scenario and propose Proposition 2.

Proposition 2. Given $\left(A^{2}+8 g\right) / 8<\kappa<\left[16(7 A+16 \psi) g+A^{2}(32 \psi-7 A) / 16(A+16 \psi)\right]$ and $g>1$, the level of green innovation efforts and the unit subsidy for green innovation in equilibrium are:

$$
\left\{e^{I S}, g^{I S}\right\}=\left\{\frac{7 A+16 \psi}{32 \kappa-7 A^{2}}, \frac{3 A \kappa-2\left(A^{2}-8 \kappa\right) \psi}{7 A+16 \psi}\right\} .
$$

Proposition 2 shows the optimal level of green innovation efforts and the unit green innovation subsidy provided to the manufacturer. Under the green product price subsidy, there is no minimum unit subsidy (i.e., $\tau$ ) requirement, but the green innovation unit subsidy must be higher than the minimum unit subsidy (i.e., $g>1$ ) to obtain the optimal solution.

Proof. Please see Appendix A.

\subsection{Scenario 3: Subsidize Both the Retailer and the Manufacturer}

The government subsidizes both the retailer and the manufacturer under the both-subsidy scheme, which is a combination of Scenarios 1 and 2. The profits of the retailer, the manufacturer and the government are:

$$
\begin{gathered}
\max _{p} \pi_{r}=(p-w) D+\tau D, \\
\max _{w, e} \pi_{m}=(w-\beta e) D-\kappa e^{2}+g e^{2}, \\
\max _{g} \pi_{g}=\psi e-\tau D-g e^{2}+\pi_{r}+\pi_{m}+D^{2} / 2 .
\end{gathered}
$$

By backward induction, we can get the equilibrium decisions of the manufacturer and the government in Proposition 3. 
Proposition 3. Given $\kappa>\left[(1-\beta)^{2}+8 g\right] / 8, g>0$ and $2 \kappa>A^{2}$, the level of green innovation efforts invested by the manufacturer, the unit price subsidy, and the unit green innovation effort subsidy provided by the government in equilibrium are:

$$
\left\{e^{B S}, \tau^{B S}, g^{B S}\right\}=\left\{\frac{A+\psi}{2 \kappa-A^{2}}, \frac{6 \kappa+3 A \psi}{2 \kappa-A^{2}}, \frac{\left.\left(2 \kappa-A^{2}\right) \psi\right)}{2(A+\psi)}\right\}
$$

To ensure all decision variables are positive, we assume that $2 \kappa>A^{2}$ in this scenario.

Proof. Please see Appendix A.

Corollary 1. Given $\kappa>\left[(1-\beta)^{2}+8 g\right] / 8, g>0$ and $2 \kappa>A^{2}$, the optimal unit green product price subsidy and green innovation effort subsidy in Scenario 3 have the following properties (see Table 4):

(i) $\partial g^{B S} / \partial \beta>0, \partial \tau^{B S} / \partial \beta<0$. With the increase of production costs, the government subsidizes the manufacturer with a higher unit green innovation subsidy, subsidizing the retailer with a lower unit price subsidy.

(ii) $\partial g^{B S} / \partial \kappa>0, \partial \tau^{B S} / \partial \kappa<0$. As the cost of green innovation efforts increases, the government provides the manufacturer with a higher unit green innovation subsidy, providing the retailer with a lower unit price subsidy.

(iii) $\partial g^{B S} / \partial \psi>0, \partial \tau^{B S} / \partial \psi>0$. The higher is the marginal benefit in the effort level, the higher is the unit subsidy of green innovation and the higher is the unit price subsidy provided by the government.

For manufacturers, green innovation efforts increase production costs, so the motivation for green innovation is low. The government needs to provide higher subsidies to manufacturers to encourage green innovation while reducing price subsidies to retailers. This is mainly because, on the one hand, the government's budget is so limited that it can better meet the subsidies to manufacturers by reducing subsidies to retailers. On the other hand, low levels of green innovation efforts are mainly attributable to higher production costs and have little to do with retailers' sales. For these reasons, the government will reduce subsidies to the retailer. In addition, the reasons for the impact of green innovation effort costs on the government are the same as the reasons for production costs.

When the marginal benefit in green effort level is high, a small increase in the level of efforts will increase the government's benefits. The government is paying more attention to the benefits of green innovation efforts. To improve the level of green efforts, the government can indirectly stimulate manufacturers' level of green innovation efforts by promoting sales of green products, or directly improve the level of green innovation efforts by encouraging the manufacturer. Therefore, the government will increase subsidies to both the retailer and the manufacturer, because the increase of these two subsidies can improve the government's utility.

Proof. Please see Appendix A.

The equilibrium values of the decision variables as well as the profits of retailers and manufacturers under the green product price subsidy, green innovation effort subsidy, and both-subsidy schemes are given in Table 2. 
Table 2. Equilibrium solutions and profits under these three scenarios.

\begin{tabular}{cccc}
\hline Optimal Solutions & Scenario 1 & Scenario 2 & Scenario 3 \\
\hline$\tau^{*}$ & $\frac{12 \kappa^{2}-A\left(A^{2} \psi-8 \kappa \psi\right)}{4 \kappa^{2}-2 A^{2} \kappa}$ & - & $\frac{6 \kappa+3 A \psi}{2 \kappa-A^{2}}$ \\
$g^{*}$ & - & $\frac{3 A \kappa-2\left(A^{2}-8 \kappa\right) \psi}{7 A+16 \psi}$ & $\frac{\left(2 \kappa-A^{2}\right) \psi}{2(A+\psi)}$ \\
$e^{*}$ & $\frac{A^{2} \psi+2 A \kappa}{4 \kappa^{2}-2 A^{2} \kappa}$ & $\frac{7 A+16 \psi}{32 \kappa-7 A^{2}}$ & $\frac{A+\psi}{2 \kappa-A^{2}}$ \\
$w^{*}$ & $\frac{(A \beta+4 \kappa)(A \psi+2 \kappa)}{4 \kappa^{2}-2 A^{2} \kappa}$ & $\frac{\beta(7 A+8 \psi)+8(2 \kappa+\psi)}{32 \kappa-7 A^{2}}$ & $\frac{\beta(A-\psi)+2(2 \kappa+\psi)}{2 \kappa-A^{2}}$ \\
$p^{*}$ & $\frac{A^{2} \psi+2 A \kappa(\beta-\psi)}{4 \kappa^{2}-2 A^{2} \kappa}$ & $\frac{\beta(7 A+4 \psi)+12(2 \kappa+\psi)}{32 \kappa-7 A^{2}}$ & $\frac{\beta(A+\psi)}{2 \kappa-A^{2}}$ \\
$\pi_{r}^{*}$ & $\frac{(2 \kappa+A \psi)^{2}}{\left(A^{2}-2 \kappa\right)^{2}}$ & $\frac{16(2 \kappa+A \psi)^{2}}{\left(32 \kappa-7 A^{2}\right)^{2}}$ & $\frac{(2 \kappa+A \psi)^{2}}{\left(A^{2}-2 \kappa\right)^{2}}$ \\
$\pi_{m}^{*}$ & $\frac{\left(8 \kappa-A^{2}\right)(2 \kappa+A \psi)^{2}}{4\left(A^{2}-2 \kappa\right)^{2} \kappa}$ & $\frac{4 \kappa+2 A \psi}{32 \kappa-7 A^{2}}$ & $\frac{(2 \kappa+A \psi)\left(3 A \psi+8 \kappa-A^{2}\right)}{2\left(A^{2}-2 \kappa\right)^{2}}$ \\
$\pi_{g}^{*}$ & $\frac{(2 \kappa+A \psi)^{2}}{8 \kappa^{2}-4 A^{2} \kappa}$ & $\frac{7 \kappa+(7 A+8 \psi) \psi}{32 \kappa-7 A^{2}}$ & $\frac{2 \kappa+\psi(2 A+\psi)}{4 \kappa-2 A^{2}}$ \\
\hline
\end{tabular}

Note: $A=1-\beta, E=\kappa-g$.

\subsection{Comparison of Subsidy Schemes}

We compare the levels of green innovation efforts under the three subsidy schemes to choose the best government subsidy policy. From the perspective of the government, the purpose of government subsidies is to raise the level of green innovation, that is, to promote the level of green efforts of manufacturers. Therefore, the best subsidy scheme is a solution that maximizes green innovation efforts.

Lemma 1. The equilibrium level of green efforts under the three subsidy schemes satisfies the following relationships:

(i) $e^{B S}>e^{I S}>e^{P S}$, when $\psi$ is large enough; and

(ii) $e^{B S}>e^{P S}>e^{I S}$, otherwise.

Lemma 1 shows the difference in green effort levels among the three subsidy schemes. When the government's marginal benefit in the effort level is relatively large, the level of green efforts under the green innovation subsidy scheme is higher than that under the green product price subsidy scheme. Otherwise, the level of green efforts under the green innovation subsidy scheme is lower than that under the green product price subsidy scheme. Among the three subsidy schemes, the scheme of providing subsidies to both retailers and manufacturers brings the highest level of green efforts regardless of the marginal benefit of the government in the level of green efforts.

From the perspective of regulators, Lemma 1 indicates that, if the government can adopt only one subsidy scheme that subsidizes retailers or subsidizes manufacturers, then, when the government's marginal benefit in green efforts is relatively high, the government needs to provide the manufacturer with green innovation subsidies to achieve the best level of green efforts. Otherwise, the government should provide retailers with product price subsidies to achieve high levels of green efforts. If the government can provide subsidies to retailers and manufacturers at the same time, then the government's best choice is undoubtedly the both-subsidy scheme, which is better than the price subsidy and the green effort subsidy in terms of the level of green innovation efforts.

Proof. Please see Appendix A.

\section{Cooperation Contract Models}

Through the above analysis of government subsidy schemes, we know that the both-subsidy scheme is the most effective way to promote the development of green innovation. In addition, the choice of cooperation contract determines whether partners can successfully play a synergistic role in green innovation [55]. In fact, the retailer can build friendly strategic partnerships with 
manufacturers to share revenue or costs [20]. Therefore, in this section, we study the choice of cooperative contracts (including the revenue-sharing and cost-sharing contract) between the retailer and the manufacturer under the premise of the government's optimal subsidy scheme.

The game sequence of the three-stage game is shown in Figure 3. Under the established optimal government subsidy scheme, the retailer determines the sharing ratio of the cooperation contract in Stage 1. In Stage 2, the manufacturer sets wholesale prices and levels of green innovation efforts. In Stage 3, the retailer determines the retail price.

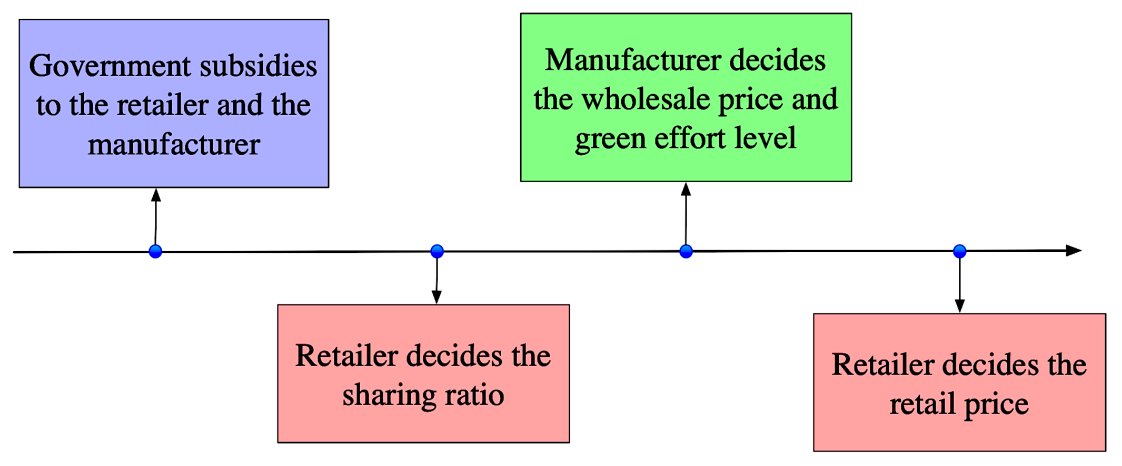

Figure 3. Timeline of the event.

\subsection{Revenue Sharing Contract}

We first establish and analyze the model of the revenue-sharing contract between the retailer and the manufacturer in a green supply chain. We then try to determine the optimal level of green innovation efforts and the profits of the retailer and manufacturer under the revenue-sharing contract.

The cooperation between the retailer and manufacturer is based on a revenue-sharing contract with parameters $\left(w, 1-\lambda_{1}\right)$, where $\lambda_{1}$ is the share of the revenue generated from a per unit of products that the manufacturer keeps, and $w$ is the wholesale price paid by the retailer to the manufacturer $[23,56,57]$. We assume $0<\lambda_{1} \leq 1$. According to the revenue-sharing contract, the expected profits of the retailer and the manufacturer are:

$$
\begin{gathered}
\max _{p, \lambda_{1}} \pi_{r}=\left(\left(1-\lambda_{1}\right) p-w\right) D+\tau D, \\
\max _{w, e} \pi_{m}=(w-\beta e) D-\kappa e^{2}+\lambda_{1} p D+g e^{2} .
\end{gathered}
$$

In Equation (15), the retailer keeps $1-\lambda_{1}$ percentage of the total revenue. Therefore, we calculate the optimal level of green innovation efforts and the profits of the retailer and the manufacturer under the revenue-sharing contract.

Proposition 4. Given $\kappa>4 g$ and $A^{2}<2\left(1+\lambda_{1}\right) E$, the equilibrium values of revenue sharing ratio, the level of green innovation efforts, the profits of the retailer and the manufacturer under the revenue-sharing contract are:

$$
\begin{gathered}
\left\{\lambda_{1}^{*}, e^{R S}\right\}=\left\{\frac{A^{2}}{4 E}, \frac{A(1+\tau)}{8 E-2 A^{2}}\right\}, \\
\left\{\pi_{r}^{R S}, \pi_{m}^{R S}\right\}=\left\{\frac{(1+\tau)^{2} E}{2\left(8 E-2 A^{2}\right)}, \frac{(1+\tau)^{2} E}{2\left(4 E-A^{2}\right)}\right\} .
\end{gathered}
$$

Proof. Please see Appendix A. 


\subsection{Cost Sharing Contract}

We analyze the cost-sharing contract between the retailer and the manufacturer. Under the cost-sharing contract, the manufacturer charges the retailer a wholesale price of $w$ for each unit of product purchase. In addition, the retailer bears $1-\lambda_{2}$ proportion of green innovation effort costs and the manufacturer bears $\lambda_{2}$ proportion of the costs. We assume that $0<\lambda_{2} \leq 1$. Then, the profits of the retailer and the manufacturer are:

$$
\begin{gathered}
\max _{p, \lambda_{2}} \pi_{r}=(p-w) D-\left(1-\lambda_{2}\right) \kappa e^{2}+\tau D, \\
\max _{w, e} \pi_{m}=(w-\beta e) D-\lambda_{2} \kappa e^{2}+g e^{2} .
\end{gathered}
$$

By backward induction, we can derive the equilibrium decision values of the manufacturer and the retailer and present these results in Proposition 5.

Proposition 5. Given $8\left(\lambda_{2} \kappa-g\right)>A^{2}$ and $16 g+16\left(2 \lambda_{2}-3\right) \kappa+5 A^{2}<0$, the equilibrium values of the cost-sharing ratio, the level of green efforts, the profits of the retailer and the manufacturer under the cost-sharing contract are:

$$
\begin{gathered}
\left\{\lambda_{2}^{*}, e^{C S}\right\}=\left\{1-\frac{A^{2}}{16 \kappa}, \frac{2 A(1+\tau)}{16 E-3 A^{2}}\right\} \\
\left\{\pi_{r}^{C S}, \pi_{m}^{C S}\right\}=\left\{\frac{\left(16 E+A^{2}\right)(1+\tau)^{2}}{8\left(32 E-6 A^{2}\right)}, \frac{\left(16 E-A^{2}\right)(1+\tau)^{2}}{4\left(32 E-6 A^{2}\right)}\right\} .
\end{gathered}
$$

Proof. Please see Appendix A.

The equilibrium values decision variables and the profits of the retailer and the manufacturer under the revenue-sharing and cost-sharing contracts are summarized in Table 3.

Table 3. Equilibrium solutions and profits under two contracts.

\begin{tabular}{ccc}
\hline Optimal Solutions & Revenue Sharing Contract & Cost Sharing Contract \\
\hline$\lambda_{*}$ & $\frac{A^{2}}{4 E}$ & $\frac{16 \kappa-A^{2}}{16 \kappa}$ \\
$e^{*}$ & $\frac{A(1+\tau)}{8 E-2 A^{2}}$ & $\frac{2 A(1+\tau)}{16 E-3 A^{2}}$ \\
$w^{*}$ & $\frac{A(\tau-1+2 \beta)+4(1+\tau) E}{8 E}$ & $\frac{(16 E+5 A \beta-A)(1+\tau)}{32 E-6 A^{2}}$ \\
$p^{*}$ & $\frac{A(\tau-1+2 \beta)+2(3-\tau) E}{8 E-2 A^{2}}$ & $\frac{3+\beta^{2}(11-\tau)+16 E(\tau-3)-9 \tau+\beta(10 \tau-14)}{2\left(6 A^{2}-32 E\right)}$ \\
$\pi_{r}^{*}$ & $\frac{(1+\tau)^{2} E}{2\left(8 E-2 A^{2}\right)}$ & $\frac{\left(16 E+A^{2}\right)(1+\tau)^{2}}{8\left(32 E-6 A^{2}\right)}$ \\
$\pi_{m}^{*}$ & $\frac{(1+\tau)^{2} E}{2\left(4 E-A^{2}\right)}$ & $\frac{\left(16 E-A^{2}\right)(1+\tau)^{2}}{4\left(32 E-6 A^{2}\right)}$ \\
\hline
\end{tabular}

\subsection{Comparison of Cooperation Contracts}

We compare the equilibrium value of green innovation efforts and the profits of the retailer and the manufacturer under the revenue-sharing contract and the cost-sharing contract and present the comparison results in Lemma 2.

Lemma 2. The comparison between the level of green efforts as well as the profits under the revenue-sharing contract and the level of green efforts as well as the profits under the cost-sharing contract satisfies the following relationship:

(i) $e^{R S}>e^{C S}$; 
(ii) $\pi_{r}^{R S}>\pi_{r}^{C S}$; and

(iii) $\pi_{m}^{R S}>\pi_{m}^{C S}$.

Lemma 2 shows the difference among these two cooperative contracts in terms of the green innovation efforts, the profits of the retailer and the manufacturer, and points out that the revenue-sharing contract is superior to the cost-sharing contract in these three aspects. The result provides an answer to what kind of cooperation contract the supply chain members should choose after receiving government subsidies.

Contrary to intuition, the revenue-sharing contract is more effective at increasing the level of green innovation efforts of manufacturers than the cost-sharing contract that directly shares costs. Moreover, the profits of the retailer and the manufacturer are also better under the revenue-sharing contract than those under the cost-sharing contract. High manufacturers' green innovation efforts will increase consumer demand for green products, thereby increasing the retailer's profits. The manufacturer can benefit from increased demand through the revenue-sharing contract. Therefore, under the revenue-sharing contract, if the manufacturer improves the level of green innovation efforts, it can increase the profits of both the retailer and the manufacturer.

Through the comparisons and discussion of green effort decisions and profits under the two cooperative contracts, we can obtain interesting managerial findings. Cooperation between supply chain partners is a necessary means to improve the environmental performance of a supply chain. In particular, the revenue-sharing contract can achieve a higher level of green innovation efforts than the cost-sharing contract. In addition, the profits of the retailer and the manufacturer under the revenue-sharing contract is higher than those under the cost-sharing contract. If the upstream manufacturer and the downstream retailer can reach a revenue-sharing contract, a win-win situation for environmental improvement and profit growth can be achieved.

Proof. Please see Appendix A.

Lemma 3. The sharing ratio under the revenue-sharing contract decreases in $\beta$ and $\kappa$, while increasing in $\psi$ (see Table 4).

Table 4. Results of sensitivity analysis.

\begin{tabular}{ccccc}
\hline Parameters & $\tau^{B S}$ & $g^{B S}$ & $\lambda_{1}^{*}$ & $\lambda_{2}^{*}$ \\
\hline$\beta$ & $\searrow$ & $\nearrow$ & $\searrow$ & $\nearrow$ \\
$\kappa$ & $\searrow$ & $\nearrow$ & $\searrow$ & $\nearrow$ \\
$\psi$ & $\nearrow$ & $\nearrow$ & $\nearrow$ & $*$ \\
\hline
\end{tabular}

Note: $\searrow$ and $\nearrow$ denote 'the result is decreasing and increasing in parameter', respectively. $*$ means that there is no impact.

Lemma 3 shows that the higher is the government's marginal benefit in green efforts, the greater is the revenue-sharing ratio between the retailer and the manufacturer. The high marginal benefit of the government indicates that the government is concerned about raising the level of green innovation efforts, thus the government will increase subsidies to retailers and manufacturers, thereby affecting the revenue-sharing ratio.

However, higher production costs and higher green innovation effort costs result in a decline in the revenue-sharing ratio between retailers and manufacturers. This is because increases in both costs lead to a decline in government subsidies for retailers, which is consistent with Corollary 1 , thus retailers will reduce the proportion of revenue shared with the manufacturer to maximize their own profits.

Proof. Please see Appendix A. 
Lemma 4. The sharing ratio under the cost-sharing contract increases in $\beta$ and $\kappa$, while is independent of $\psi$ (see Table 4).

Lemma 4 shows that the cost-sharing ratio increases with the cost of production and the cost of green innovation efforts, but has nothing to do with the marginal benefit in green efforts. This indicates that, under the cost-sharing contract, the retailer only considers the cost factor when determining the cost-sharing ratio, regardless of the government subsidy factor. In addition, the higher is the cost of production or the green innovation efforts, the higher is the cost of the manufacturer, thereby increasing the cost-sharing ratio.

Proof. Please see Appendix A.

\section{Numerical Experiment}

In this section, we provide a numerical example to illustrate the above results. Through numerical examples, we can intuitively examine the research results, such as the impact of production costs and green innovation effort costs on the level of green innovation efforts, as well as the profits of the retailer and the manufacturer under the revenue-sharing contract and the cost-sharing contract. The numerical example also shows the impact of the marginal benefit in green efforts on the level of green efforts and profits.

\subsection{Analysis of the Impact of the Production Cost on Green Efforts and Profits}

We analyze the impact of production costs on green effort levels and profits. Assuming that $\kappa=1$, $\psi=1$, we set $\beta$ as the independent variable. We can check in the previous section to see if the values of these parameters meet all of the above conditions. We show the results in Figure 4.

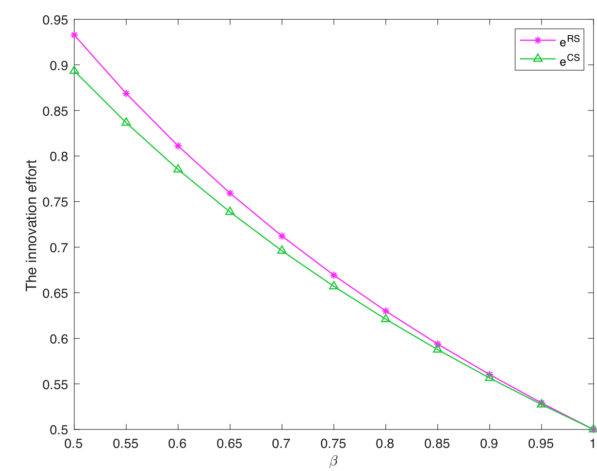

(a)

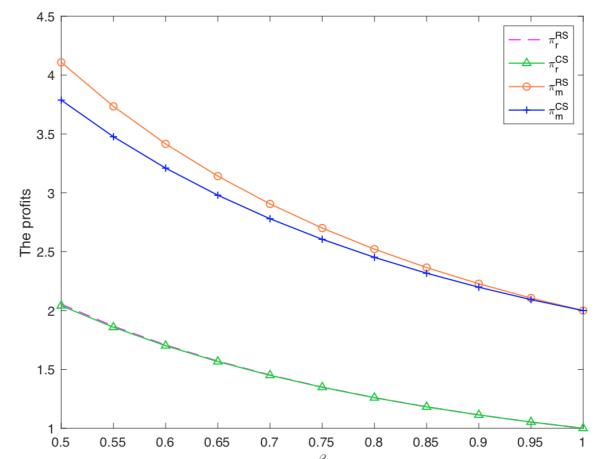

(b)

Figure 4. The impact of the production cost on the green effort level and profits: (a) the level of green innovation efforts; and (b) the profits of the retailer and the manufacturer under the revenue-sharing contract and the cost-sharing contract.

Figure 4a implies that the level of green innovation efforts under the revenue-sharing contract is higher than that under the cost-sharing contract. However, as $\beta$ increases, the level of green innovation efforts under these two contracts will decrease. This means that increased production costs are not conducive to the improvement of green innovation efforts.

As can be seen in Figure $4 \mathrm{~b}$, both the retailer and the manufacturer's profits are negatively related to production costs, whether they are under a revenue-sharing contract or not. The higher the cost of production, the lower the profit. In addition, an interesting finding is that the manufacturer's profit is always higher than the retailer's profit regardless of the contract. 


\subsection{Analysis of the Impact of the Green Innovation Effort Cost on Equilibrium Decisions and Profits}

To illustrate how the cost of green efforts affects the level of green innovation efforts and the profits of the retailer and the manufacturer, we set the parameters' values $\beta=0.5$ and $\psi=1$, and $\kappa$ as the independent variable. The numerical results are shown in Figure 5.

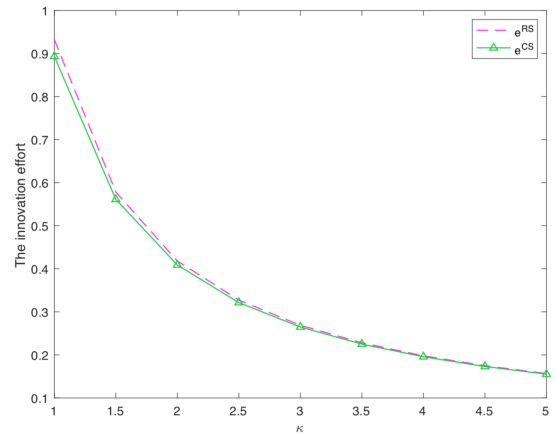

(a)

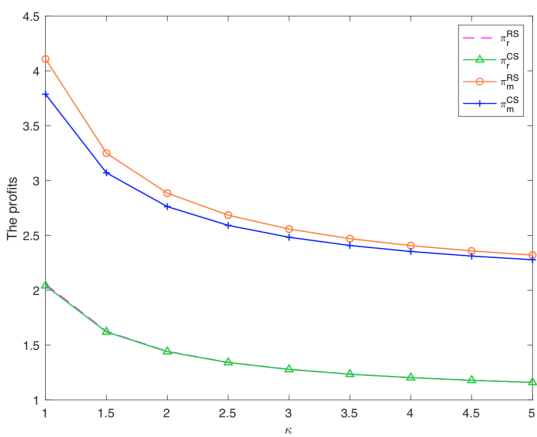

(b)

Figure 5. The impact of the green innovation cost on the level of green innovation efforts and profits under the revenue-sharing contract and the cost-sharing contract: (a) the level of green innovation efforts; and (b) the profits of the retailer and the manufacturer.

Figure 5a presents the level of green innovation efforts under the revenue-sharing contract and the cost-sharing contract. As can be seen in the figure, the level of green efforts is negatively related to the cost of green innovation. This means that the increase in the cost of green innovation is not conducive to improving the level of green innovation efforts. In addition, the level of green efforts under the revenue-sharing contract is higher than that under the cost-sharing contract, which is consistent with Lemma 2 (i).

As shown in Figure 5b, the profits of the retailer and the manufacturer decrease with the increase of green innovation costs, which indicates that higher green innovation costs will reduce the benefits of supply chain members. In addition, when the supply chain is coordinated by a revenue-sharing contract, the profits of the retailer and the manufacturer are greater than those under the cost-sharing contract, which verifies Lemma 2.

\subsection{Analysis of the Impact of the Marginal Benefit in the Green Effort on Equilibrium Decisions and Profits}

To show the relationship among $\psi, e$, and $\pi$, we present Figure 6, where the values of the parameters are $\beta=0.5$ and $\kappa=1$, and $\psi$ is an independent variable.

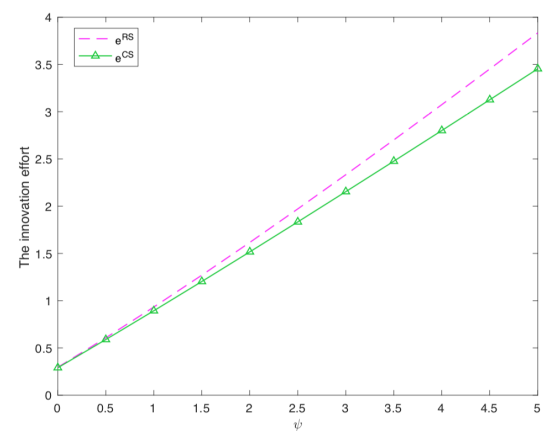

(a)

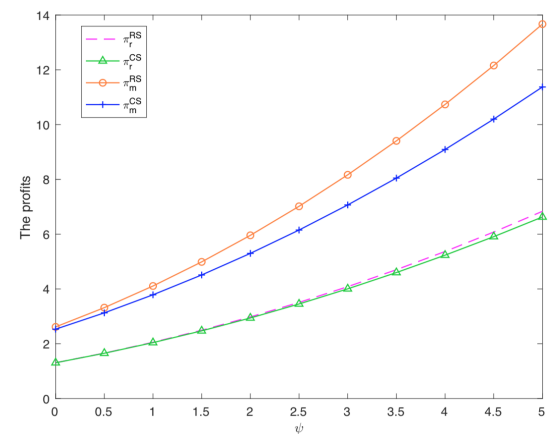

(b)

Figure 6. The impact of the marginal benefit in green efforts on the level of green innovation efforts and profits under the revenue-sharing contract and the cost-sharing contract: (a) the level of green innovation efforts; and (b) the profits of the retailer and the manufacturer. 
As can be seen in Figure 6a, under the revenue-sharing contract and the cost-sharing contract, the level of green innovation efforts increases with the increase of the marginal benefit in green innovation efforts. This is because the more benefits the government receives from green innovation efforts, the more subsidies they will provide to the retailer and the manufacturer, and the increased subsidies will increase the level of green innovation efforts.

From the results in Figure 6b, we can know that the profits of the retailer and the manufacturer under the revenue-sharing contract and the cost-sharing contract increase with the increase of the marginal benefit in green efforts. In particular, the profits of the retailer and the manufacturer under the revenue-sharing contract are greater than those under the cost-sharing contract.

\section{Discussion}

Green product innovation has long been a key avenue for revenue and profit growth [2] and mitigating environmental impact [4]. Many scholars (for example, Hong and Guo [5], Ghosh and Shah [20], and Zhu and He [36]) have paid attention to the impact of green innovation investment on product greenness and pricing strategies with the assumption that green innovation investment has no impact on production costs, and have shown that the green innovation investment will improve the greenness of products. This paper differs from previous green innovation literature in terms of research object and hypothesis. We concentrate on the joint impact of government subsidies and cooperative contracts on green innovation. Moreover, we assume that green innovation efforts will lead to an increase in production costs, which is more in line with the reality of green innovation. Based on this new hypothesis, our research shows that the government should subsidize both retailers and manufacturers to promote the development of green innovation, which enriches the literature on green innovation.

To promote the development of green innovation, governments often use incentive and deterrent policies to exert positive and negative external influences on enterprises [17,37-39]. In recent years, researchers have conducted quantitative research on the impact of government intervention on green supply chain decision-making. Mitra and Webster [4], Xue et al. [26], and Raz and Ovchinnikov [27] agree that government subsidies can promote the development of green innovation through game model analysis. However, they mostly focus on the hypothesis that government subsidies are exogenous and constant. In this paper, we endogenize government subsidies into green innovation decision-making and attempts to answer the question of who should receive government subsidies to achieve the best policy outcomes for green innovation. The research of Chen et al. [13] is most relevant to our work in terms of edogenizing government subsidies and exploring the impact of government subsidies on sustainable innovation. In their research, they endogenized government subsidies into research joint ventures (RJV) and considered the impacts of two types of subsidies (per-unit production subsidy and innovation effort subsidy) on the level of innovation efforts. We differ from them in the sequence of studies on government subsidies and contracts. We first determine the best government subsidy scheme. Then, we combine the optimal government plan with two cooperative contracts to consider the influence of government subsidies on cooperative contracts, which has expanded the research of Chen et al. [13].

In addition, various contractual forms have been thoroughly examined in the supply chain management literature. It is a well-established theoretical result in this literature that cooperation can improve the performance of green supply chains. Ge et al. [15], Ghosh and Shah [20], Song and Gao [25], and Talluri et al. [28] studied the impact of inter-firm cooperation on the greenness level of products and showed that cooperation is the key to promoting green development of products by sharing R\&D costs. However, few papers in this field consider the impact of government subsidies on the choice of green innovation cooperation contracts. In this paper, we investigate the impact of government subsidies on the choice of cooperative contracts to examine the impact of government subsidies on green innovation efforts indirectly. We incorporate the level of green innovation efforts into a demand function and compare among two contractual forms (revenue-sharing contract and 
cost-sharing contract). Our objective is to find the best cooperation mode by comparing different contracts under the premise of government subsidies, and to study the impact of government subsidies on cooperative contracts. Our research shows that the revenue-sharing contract is superior to the cost-sharing contract and an increase in government subsidies would raise the sharing ratio under revenue-sharing contracts, which fills the gap in the study of the impact of government subsidies on contracts.

In summary, this study attempts to fill in the research gap of jointly examining the impact of government subsidies and cooperative contracts on decision-making of green innovation efforts by considering variable production costs in models, that is, green innovation efforts increase production costs. By comparing the impact of three subsidy schemes and two cooperative contracts on green innovation efforts, we are able to find the best subsidy scheme for the government and the optimal cooperative contract for supply chain partners to promote green innovation.

\section{Conclusions}

This paper investigates the impact of government subsidies and supply chain cooperation contracts on the level of green innovation efforts that manufacturers exert to improve the sustainability of the supply chain through a three-player game model. We consider three subsidy schemes (price subsidies for retailers, green innovation subsidies for manufacturers, and subsidies for retailers and manufacturers) and two cooperation contracts (revenue-sharing contracts and cost-sharing contracts). We derive the equilibrium values of the level of green innovation efforts and firms' profits in each case. Then, we compare and discuss the equilibrium outcomes under these scenarios in terms of green innovation efforts and firms' profits. From the comparisons and discussions of the decisions among these scenarios, we obtain interesting findings and managerial insights:

- For government subsidies without cooperative contracts, we find that the both-subsidy scheme is the best choice for the government to improve the sustainability of green innovation. Under this subsidy scheme, the manufacturer can devote the most energy to green innovation.

- By comparing the revenue-sharing contract with the cost-sharing contract, we find that, under the premise of government subsidies, the revenue-sharing contract is superior to the cost-sharing contract in terms of the level of green innovation efforts and the profits of the retailer and the manufacturer.

- The numerical analysis shows that the increase in production costs and green innovation effort costs lead to a decline in the profit and the level of green innovation efforts, which is consistent with the actual situation. In addition, the increase of the marginal benefit in green efforts increases government subsidies for supply chain members, thereby raising the level of green innovation efforts.

Our research contributes to the literature on green supply chains by jointly investigating the impact of government subsidy schemes and cooperative contracts on green innovation efforts. In the operational management $(\mathrm{OM})$ literature, government incentives and cooperation contracts are widely recognized as key measures to promote the development of green innovation. To the best of our knowledge, this is the first attempt to incorporate three government subsidy schemes (subsidies for the retailer, the manufacturer, or both) and two types of cooperative contracts (revenue-sharing and cost-sharing contracts) into green innovation models using game theoretical approach. In addition, this paper considers the important practical characteristics of green innovation efforts, that is, green innovation efforts will increase production costs, thereby affecting green decision-making, which fills the research gap of green innovation literature. It also addresses two of the four research gaps (i.e., largely neglected market forces and vertically aligned sustainable strategies) identified by Tang and Zhou [29]. Considering that consumers' environmental awareness plays an important role in the investment and management of corporate sustainability, we incorporate consumers' preferences for green innovation efforts into the demand function, which addresses the first research gap of 
the largely neglected market forces. Through the analysis of the cooperation between upstream manufacturers and downstream retailers under two different contracts, the second research gap of vertically aligned sustainable strategies is filled.

Our findings also provide important management implications for governments and supply chain members to promote the development of green innovation. Many companies (e.g., IKEA, $\mathrm{H} \& \mathrm{M}$ and Levis) have rapidly begun incorporating green concepts into their product innovation plans. Governments around the world (e.g., Europe, the United States, Canada, and China) are taking incentives to reduce the high cost of green $R \& D$ and encourage firms to promote sustainability. Our results show that these incentives are essential in promoting green innovation, and that for any $R \& D$ efforts that lead to increased production costs, the government needs to subsidize both retailers and manufacturers simultaneously to achieve the best policy outcomes. This managerial insight is consistent with the government's subsidy policies for new energy vehicles. For example, green innovation efforts in the new energy vehicle industry increase production costs, and automakers are reluctant to invest in green innovation and production. In 2016, the Chinese government implemented production subsidies for manufacturers and promotional subsidies for retailers to promote the development of the new energy vehicle industry.

Another group that may benefit from our research is corporate managers who, after receiving government subsidies, undertake green innovation initiatives by signing cooperative contracts with upstream or downstream enterprises. For instance, when Walmart collaborates with its supplier Clorox to produce smaller bleach bottles, they take the revenue-sharing contract as a good way to work together. However, when they face government subsidy schemes, it is unclear which kind of cooperative contract is suitable for implementing green innovation. As noted in Lemma 2, the revenue-sharing contract is superior to the cost-sharing contract in terms of the level of green innovation efforts and the profits of retailers and manufacturers. Therefore, the revenue-sharing contract is the best cooperation mode for the two companies to carry out green innovation cooperation under the premise of government subsidies, which can achieve a win-win situation of environmental improvement and profit growth.

This research can be extended in several directions in future work. The first natural extension to the introduced model is to consider different ways of cooperation between supply chain partners in the face of government policies. In this paper, we assume that, under the premise of government subsidies, supply chain partners can choose between cost-sharing and revenue-sharing contracts for green innovation R\&D cooperation. However, in practice, enterprises adopt various forms of contracts for green innovation cooperation. For example, after China's entry into the WTO in 2001, multinational companies usually establish joint ventures with companies designated or led by the Chinese government. The second extension of the model is to consider uncertain demand functions. This paper assumes that the market demand is deterministic and that the demand function is linear. As market demand is affected by many factors, market demand is often uncertain, thus it is valuable to use uncertain variables to express linear or non-linear demand functions in future research. Lastly, incorporating other government subsidy schemes into the green supply chain model to analyze the impact of different incentives on green innovation would be interesting. As discussed in the Introduction, there are multiple forms of government subsidies available, such as marketing subsidies and purchase subsidies.

Author Contributions: All authors contribute the paper equally.

Funding: This research received no external funding.

Acknowledgments: We thank all the anonymous review experts for their advice, which is very important for the improvement of the article.

Conflicts of Interest: The authors declare no conflict of interest. 


\section{Appendix A. Proofs}

Proof of Proposition 1. Firstly, the retailer decides the retail price. From Equation (3), we can derive that $\frac{\partial^{2} \pi_{r}}{\partial^{2} p}=-2<0$, so $p^{*}(w, e, \tau)=\frac{1+e+w-\tau}{2}$. Secondly, the manufacturer decides the wholesale price and green innovation effort. We substitute the values of $p^{*}(w, e, \tau)$ into $\pi_{m}$, and the Hessian matrix is addressed as follows:

$$
\left[\begin{array}{cc}
-1 & \frac{1+\beta}{2} \\
\frac{1+\beta}{2} & -\beta-2 \kappa
\end{array}\right]=\beta+2 \kappa-\left(\frac{1+\beta}{2}\right)^{2}
$$

when $\kappa>\frac{(1-\beta)^{2}}{8}, \pi_{m}$ is a strictly concave function of $w$ and $e$ and get $e^{*}(\tau)=\frac{(1-\beta)(1+\tau)}{8 \kappa-(1-\beta)^{2}}$ and $w^{*}(\tau)=\frac{\left(\beta^{2}-\beta-4 \kappa\right)(1+\tau)}{(1-\beta)^{2}-8 \kappa}$. Thirdly, the government decides the amount of subsidy. Then, we substitute the values of $e^{*}(\tau), w^{*}(\tau), p^{*}(\tau)$ into $\pi_{g}$, and the necessary conditions for optimum subsidy $\tau$ for the government is $\frac{\partial^{2} \pi_{g}}{\partial^{2} \tau}=-\frac{2\left(2 \kappa^{2}-(1-\beta)^{2} \kappa\right)}{\left((1-\beta)^{2}-8 \kappa\right)^{2}}$. When $\kappa>\frac{(1-\beta)^{2}}{2}, \pi_{g}$ is a concave function of $\tau$ and $\tau^{P S}=\frac{12 \kappa^{2}-A\left(A^{2} \psi-8 \kappa \psi\right)}{4 \kappa^{2}-2 A^{2} \kappa}$. Because $\frac{(1-\beta)^{2}}{2}>\frac{(1-\beta)^{2}}{8}$, when $\kappa>\frac{(1-\beta)^{2}}{2}$, we get the equilibrium results as are shown in Proposition 1. The proof is completed.

Proof of Proposition 2. As the proof is similar to the proof of Proposition 1, we omit it here.

Proof of Proposition 3. As the proof is similar to the proof of Proposition 1, we omit it here.

Proof of Corollary 1. From Proposition 3, we can get the equilibrium result of $g^{B S}$ and $\tau^{B S}: g^{B S}=$ $\frac{\left(2 \kappa-A^{2}\right) \psi}{2(A+\psi)}=\frac{\left(2 \kappa-(1-\beta)^{2}\right) \psi}{2(1-\beta+\psi)}$ and $\tau^{B S}=\frac{6 \kappa+3 A \psi}{2 \kappa-A^{2}}=\frac{6 \kappa+3(1-\beta) \psi}{2 \kappa-(1-\beta)^{2}}$. Under the conditions that $\kappa>4 g$ and $2\left(1+\lambda_{1}\right)(g-\kappa)+A^{2}<0$, we can get the first-order conditions $\frac{\partial g^{B S}}{\partial \beta}=\frac{\psi\left(A^{2}+2(\kappa+A \psi)\right)}{2(A+\psi)^{2}}>0, \frac{\partial \tau^{B S}}{\partial \beta}=$ $-\frac{12 A \kappa+3\left(A^{2}+2 \kappa\right) \psi}{\left(A^{2}-2 \kappa\right)^{2}}<0, \frac{\partial g^{B S}}{\partial \kappa}=\frac{\psi}{A+\psi}>0, \frac{\partial \tau^{B S}}{\partial \kappa}=-\frac{6 A(A+\psi)}{\left(A^{2}-2 \kappa\right)^{2}}<0, \frac{\partial g^{B S}}{\partial \psi}=\frac{A\left(2 \kappa-A^{2}\right)}{2(A+\psi)^{2}}>0$ and $\frac{\partial \tau^{B S}}{\partial \psi}=$ $\frac{3 A}{2 \kappa-A^{2}}>0$. The proof is completed.

Proof of Lemma 1. Firstly, Comparing the level of green innovation effort under innovation subsidy with that under a price subsidy, $e^{I S}-e^{P S}=\frac{7 A+16 \psi}{32 \kappa-7 A^{2}}-\frac{A^{2} \psi+2 A \kappa}{4 \kappa^{2}-2 A^{2} \kappa}=\frac{64 \kappa^{2} \psi+7 A^{4} \psi-64 A^{2} \kappa \psi-36 A \kappa^{2}}{2 \kappa\left(32 \kappa-7 A^{2}\right)\left(2 \kappa-A^{2}\right)}, 1<g<\kappa$, $A=1-\beta, 0<A<1$, so, $32 \kappa-7 A^{2}>0,2 \kappa-A^{2}>0,2 \kappa\left(32 \kappa-7 A^{2}\right)\left(2 \kappa-A^{2}\right)>0$. The value of $e^{I S}-e^{P S}$ depends on the value of $64 \kappa^{2} \psi+7 A^{4} \psi-64 A^{2} \kappa \psi-36 A \kappa^{2}$. If $\psi>\frac{36 \kappa^{2}}{7 A^{3}}$, then $e^{I S}-e^{P S}>0$, otherwise, $e^{I S}-e^{P S}<0$. It illustrates that $e^{I S}>e^{P S}$ when $\psi$ is large enough. Secondly, we compare the level of green innovation effort under innovation subsidy with that under both-subsidy when $\psi$ is large enough, $e^{I S}-e^{B S}=\frac{7 A+16 \psi}{32 \kappa-7 A^{2}}-\frac{A+\psi}{2 \kappa-A^{2}}=-\frac{9 A(2 \kappa+A \psi)}{\left(7 A^{2}-32 \kappa\right)\left(A^{2}-2 \kappa\right)}$, because $2 \kappa>A^{2}, A^{2}-2 \kappa<0$, $7 A^{2}-32 \kappa<0$, we get $e^{I S}-e^{B S}<0$. We can know that when $\psi$ is large enough, $e^{B S}>e^{I S}>e^{P S}$. Secondly, when $\psi$ is small, we compare the level of green innovation effort under the price subsidy with that under both subsidy, $e^{P S}-e^{B S}=\frac{A^{2} \psi+2 A \kappa}{4 \kappa^{2}-2 A^{2} \kappa}-\frac{A+\psi}{2 \kappa-A^{2}}=-\frac{\psi}{2 \kappa}<0$. When $\psi$ is small, we get $e^{B S}>e^{P S}>e^{I S}$. The proof is completed.

Proof of Proposition 4. Firstly, the retailer decides the retail price. From Equation (15), we can derive that $\frac{\partial^{2} \pi_{r}}{\partial^{2} p}=-2+2 \lambda_{1}<0$, so $p^{*}\left(w, e, \lambda_{1}\right)=\frac{1+w+e\left(1-\lambda_{1}\right)-\lambda_{1}-\tau}{2\left(1-\lambda_{1}\right)}$. Secondly, the manufacturer decides the wholesale price and green innovation effort. We substitute the values of $p^{*}\left(w, e, \lambda_{1}\right)$ into $\pi_{m}$, and the Hessian matrix is addressed as follows:

$$
\left[\begin{array}{cc}
-\frac{1}{1-\lambda_{1}}-\frac{\lambda_{1}}{2\left(1-\lambda_{1}\right)^{2}} & \frac{1-\lambda_{1}+\beta}{2\left(1-\lambda_{1}\right)} \\
\frac{1-\lambda_{1}+\beta}{2\left(1-\lambda_{1}\right)} & \frac{4 g+\lambda_{1}-2 \beta-4 \kappa}{2}
\end{array}\right]=\frac{4\left(2-\lambda_{1}\right)(\kappa-4 g)+(1-\beta)^{2}}{4\left(1-\lambda_{1}\right)^{2}}>0 .
$$

when $\kappa>4 g, \pi_{m}$ is a strictly concave function of $w$ and $e$ and get $e^{*}\left(\lambda_{1}\right)=\frac{A(1+\tau)}{4\left(2-\lambda_{1}\right)(\kappa-g)-A^{2}}$ and $w^{*}\left(\lambda_{1}\right)=\frac{(A \beta+4 \kappa C) C+\left(4 \kappa-A \lambda_{1}+A \beta\right) \tau-4 g\left(\tau+C^{2}\right)}{4\left(2-\lambda_{1}\right)(\kappa-g)-A^{2}}$. Thirdly, the retailer decides revenue-sharing ratio: $\frac{\partial^{2} \pi_{r}}{\partial^{2} \lambda_{1}}=$ 
$-\frac{64(g-\kappa)^{3}\left(2\left(1+\lambda_{1}\right)(g-\kappa)+A^{2}\right)(1+\tau)^{2}}{\left(4\left(2-\lambda_{1}\right)(g-\kappa)+A^{2}\right)^{4}}$, when $2\left(1+\lambda_{1}\right)(g-\kappa)+A^{2}<0$, we get the optimal value $\lambda_{1}^{*}=\frac{A^{2}}{4 E}$ and the equilibrium results in Proposition 4 . The proof is completed.

Proof of Proposition 5. As the proof is similar to the proof of Proposition 4, we omit it here.

Proof of Lemma 2. We firstly compare the level of green innovation effort under the revenue-sharing contract with that under the cost-sharing contract, $e^{R S}-e^{C S}=\frac{A(1+\tau)}{8 E-2 A^{2}}-\frac{2 A(1+\tau)}{16 E-3 A^{2}}=\frac{A^{3}(1+\tau)}{2\left(4 E-3 A^{2}\right)\left(16 E-3 A^{2}\right)}$, as $E=\kappa-g>0, A=1-\beta>0, \tau>0,0<\lambda_{1}<1, A^{2}<2\left(1+\lambda_{1}\right) E, A^{2}<4 E$, we can get that $4 E-A^{2}>0,16 E-3 A^{2}>0$. Thus, $e^{R S}-e^{C S}>0$. Secondly, we compare the profit of the retailer under these two contracts, $\pi_{r}^{R S}-\pi_{r}^{C S}=\frac{(1+\tau)^{2} E}{2\left(8 E-2 A^{2}\right)}-\frac{\left(16 E+A^{2}\right)(1+\tau)^{2}}{8\left(32 E-6 A^{2}\right)}=\frac{A^{4}(1+\tau)^{2}}{16\left(4 E-A^{2}\right)\left(16 E-3 A^{2}\right)}>0$. Thus, $\pi_{r}^{R S}>\pi_{r}^{C S}$. Lastly, we compare the profit of the manufacturer under these two contracts, $\pi_{m}^{R S}-\pi_{m}^{C S}=$ $\frac{(1+\tau)^{2} E}{2\left(4 E-A^{2}\right)}-\frac{\left(16 E-A^{2}\right)(1+\tau)^{2}}{4\left(32 E-6 A^{2}\right)}=\frac{A^{2}\left(8 E-A^{2}\right)(1+\tau)^{2}}{8\left(16 E-3 A^{2}\right)\left(4 E-A^{2}\right)}>0$. Thus, $\pi_{m}^{R S}>\pi_{m}^{C S}$. The proof is completed.

Proof of Lemma 3. From Proposition 4, we can get that $\lambda_{1}^{*}=\frac{A^{2}}{4 E}=\frac{(1-\beta)^{2}}{4(\kappa-g)}$. Under the conditions that $\kappa>4 g$ and $A^{2}<2\left(1+\lambda_{1}\right) E$, we can get the first-order conditions: $\frac{\partial \lambda_{1}^{*}}{\partial \beta}=-\frac{A^{2} \psi+2 \kappa(2 A+\psi)}{2(2 \kappa+A \psi)^{2}}<0$, $\frac{\partial \lambda_{1}^{*}}{\partial \kappa}=-\frac{A(A+\psi)}{(2 \kappa+A \psi)^{2}}<0$, and $\frac{\partial \lambda_{1}^{*}}{\partial \psi}=\frac{A\left(2 \kappa-A^{2}\right)}{2(2 \kappa+A \psi)^{2}}>0$. The proof is completed.

Proof of Lemma 4. From Proposition 5, we can get that $\lambda_{2}^{*}=1-\frac{A^{2}}{16 \kappa}=1-\frac{(1-\beta)^{2}}{16 \kappa}$. Under the conditions that $8\left(\lambda_{2} \kappa-g\right)>A^{2}$ and $16 g+16\left(2 \lambda_{2}-3\right) \kappa+5 A^{2}<0$, we can get the first-order conditions $\frac{\partial \lambda_{2}^{*}}{\partial \beta}=\frac{A}{8 \kappa}$ and $\frac{\partial \lambda_{2}^{*}}{\partial \kappa}=\frac{(1-\beta)^{2}}{16 \kappa^{2}}>0$. The proof is completed.

\section{References}

1. Chen, X.; Benjaafar, S.; Elomri, A. On the effectiveness of emission penalties in decentralized supply chains. Eur. J. Oper. Res. 2019, 274, 1155-1167. [CrossRef]

2. Bhaskaran, S.R.; Krishnan, V. Effort, revenue, and cost sharing mechanisms for collaborative new product development. Manage. Sci. 2009, 55, 1152-1169. [CrossRef]

3. Yenipazarli, A. To collaborate or not to collaborate: Prompting upstream eco-efficient innovation in a supply chain. Eur. J. Oper. Res. 2017, 260, 571-587. [CrossRef]

4. Mitra, S.; Webster, S. Competition in remanufacturing and the effects of government subsidies. Int. J. Prod. Econ. 2008, 111, 287-298. [CrossRef]

5. Hong, Z.; Guo, X. Green product supply chain contracts considering environmental responsibilities. Omega 2019, 83, 155-166. [CrossRef]

6. Zhang, Z.; Wang, Y.T.; Meng, Q.C.; Luan, X.Y. Impacts of green production decision on social welfare. Sustainability 2019, 11, 453. [CrossRef]

7. Gong, Y.; Jia, F.; Brown, S.; Koh, L. Supply chain learning of sustainability in multi-tier supply chains: A resource orchestration perspective. Int. J. Oper. Prod. Man. 2018, 38, 1061-1090. [CrossRef]

8. Dong, C.; Shen, B.; Chow, P.-S.; Yang, L.; Ng, C.T. Sustainability investment under cap-and-trade regulation. Ann. Oper. Res. 2016, 240, 509-531. [CrossRef]

9. Chen, Y.-S.; Lai, S.-B.; Wen, C.-T. The influence of green innovation performance on corporate advantage in Taiwan. J. Bus. Ethics 2006, 67, 331-339. [CrossRef]

10. Wang, C.; Nie, P.-Y.; Peng, D.-H.; Li, Z.-H. Green insurance subsidy for promoting clean production innovation. J. Clean Prod. 2017, 148, 111-117. [CrossRef]

11. Fleischmann, M.; Kuik, R.; Dekker, R. Controlling inventories with stochastic item returns: A basic model. Eur. J. Oper. Res. 2002, 138, 63-75. [CrossRef]

12. Baade, R.A. Evaluating subsidies for professional sports in the United States and Europe: A public-sector primer. Oxford Rev. Econ. Pol. 2003, 19, 585-597. [CrossRef]

13. Chen, J.-Y.; Dimitrov, S.; Pun, H. The impact of government subsidy on supply Chains' sustainability innovation. Omega 2019, 86, 42-58. [CrossRef]

14. Linton, J. D.; Klassen, R.; Jayaraman, V. Sustainable supply chains: An introduction. J. Oper. Manag. 2007, 25, 1075-1082. [CrossRef] 
15. Ge, Z.; Hu, Q.; Xia, Y. Firms' R\&D cooperation behavior in a supply Chain. Prod. Oper. Manag. 2014, 23, 599-609.

16. Giannoccaro, I.; Pontrandolfo, P. Supply chain coordination by revenue sharing contracts. Int. J. Prod. Econ. 2004, 89, 131-139. [CrossRef]

17. Hafezalkotob, A. Competition of two green and regular supply chains under environmental protection and revenue seeking policies of government. Comput. Ind. Eng. 2015, 82, 103-114. [CrossRef]

18. Shafiq, M.; Savino, M.M. Supply chain coordination to optimize manufacturer's capacity procurement decisions through a new commitment-based model with penalty and revenue-sharing. Int. J. Prod. Econ. 2019, 208, 512-528. [CrossRef]

19. Wang, G.; Ding, P.; Chen, H.; Mu, J. Green fresh product cost sharing contracts considering freshness-keeping effort. Soft Comput. 2019, 1-21. [CrossRef]

20. Ghosh, D.; Shah, J. Supply chain analysis under green sensitive consumer demand and cost sharing contract. Int. J. Prod. Econ. 2015, 164, 319-329. [CrossRef]

21. Raza, S.A. Supply chain coordination under a revenue-sharing contract with corporate social responsibility and partial demand information. Int. J. Prod. Econ. 2018, 205, 1-14. [CrossRef]

22. Yao, Z.; Leung, S.C.H.; Lai, K.K. The effectiveness of revenue-sharing contract to coordinate the price-setting newsvendor products' supply chain. Supply Chain Manag. 2008, 13, 263-271. [CrossRef]

23. Cachon, G.P.; Lariviere, M.A. Supply chain coordination with revenue-sharing contracts: Strengths and limitations. Manag. Sci. 2005, 51, 30-44. [CrossRef]

24. Zhou, Y.; Bao, M.; Chen, X.; Xu, X. Co-op advertising and emission reduction cost sharing contracts and coordination in low-carbon supply chain based on fairness concerns. J. Clean Prod. 2016, 133, 402-413. [CrossRef]

25. Song, H.; Gao, X. Green supply chain game model and analysis under revenue-sharing contract. J. Clean Prod. 2018, 170, 183-192. [CrossRef]

26. Xue, J.; Gong, R.; Zhao, L.; Ji, X.; Xu, Y. A Green supply-chain decision model for energy-saving products that accounts for government subsidies. Sustainability 2019, 11, 2209. [CrossRef]

27. Raz, G.; Ovchinnikov, A. Coordinating pricing and supply of public interest goods using government rebates and subsidies. IEEE Trans. Eng. Manag. 2015, 62, 65-79. [CrossRef]

28. Talluri, S.; Narasimhan, R.; Chung, W. Manufacturer cooperation in supplier development under risk. Eur. J. Oper. Res. 2010, 207, 165-173. [CrossRef]

29. Tang, C.S.; Zhou, S. Research advances in environmentally and socially sustainable operations. Eur. J. Oper. Res. 2012, 223, 585-594. [CrossRef]

30. Srivastava, S.K. Green supply-chain management: A state-of-the-art literature review. Int. J. Manag. Rev. 2007, 9, 53-80. [CrossRef]

31. Hafezalkotob, A. Direct and indirect intervention schemas of government in the competition between green and non-green supply chains. J. Clean Prod. 2018, 170, 753-772. [CrossRef]

32. Fahimnia, B.; Sarkis, J.; Davarzani, H. Green supply chain management: A review and bibliometric analysis. Int. J. Prod. Econ. 2015, 162, 101-114. [CrossRef]

33. Zhang, H.C.; Kuo, T.C.; Lu, H.T.; Huang, S.H. Environmentally conscious design and manufacturing: A state-of-the-art survey. J. Manuf. Syst. 1997, 16, 352-371. [CrossRef]

34. Carter, C.R.; Ellram, L.M. Reverse logistics: A review of the literature and framework for future investigation. J. Bus. Logist. 1998, 19, 85-102.

35. Ghosh, D.; Shah, J. A comparative analysis of greening policies across supply chain structures. Int. J. Prod. Econ. 2012, 135, 568-583. [CrossRef]

36. Zhu, W.; He, Y. Green product design in supply chains under competition. Eur. J. Oper. Res. 2017, 258, 165-180. [CrossRef]

37. Sheu, J.-B.; Chen, Y.J. Impact of government financial intervention on competition among green supply chains. Int. J. Prod. Econ. 2012, 138, 201-213. [CrossRef]

38. Sheu, J.-B. Bargaining framework for competitive green supply chains under governmental financial intervention. Transp. Res. Pt. E-Logist. Transp. Rev. 2011, 47, 573-592. [CrossRef]

39. Cheng, K.-F.; Tsai, C.-S.; Hsu, C.-C.; Lin, S.-C.; Tsai, T.-C.; Lee, J.-Y. Emission tax and compensation subsidy with cross-industry pollution. Sustainability 2019, 11, 998. [CrossRef] 
40. Van der Rhee, B.; van der Veen, J.A.A.; Venugopal, V.; Nalla, V.R. A new revenue sharing mechanism for coordinating multi-echelon supply chains. Oper. Res. Lett. 2010, 38, 296-301. [CrossRef]

41. Leng, M.; Parlar, M. Game-theoretic analyses of decentralized assembly supply chains: Non-cooperative equilibria vs. coordination with cost-sharing contracts. Eur. J. Oper. Res. 2010, 204, 96-104. [CrossRef]

42. Veugelers, R. Collaboration in R\&D: An assessment of theoretical and empirical findings. De Econ. 1998, $146,419-443$.

43. Brockhoff, K. R\&D Cooperation between firms-A perceived transaction cost perspective. Manag. Sci. 1992, 38, 514-524.

44. Zhang, L.; Xue, B.; Liu, X. Carbon emission reduction with regard to retailer's fairness concern and subsidies. Sustainability 2018, 10, 1209. [CrossRef]

45. Gupta, R.; Biswas, I.; Kumar, S. Pricing decisions for three-echelon supply chain with advertising and quality effort-dependent fuzzy demand. Int. J. Prod. Res. 2018, 57, 2715-2731. [CrossRef]

46. Sheffi, Y. Sustainability in Practice. J. Bus. Logist. 2018, 39, 160-163. [CrossRef]

47. Arora, A.; Ceccagnoli, M. Patent protection, complementary assets, and firms' incentives for technology licensing. Manage. Sci. 2006, 52, 293-308. [CrossRef]

48. Atasu, A.; Subramanian, R. Extended producer responsibility for E-waste: Individual or collective producer responsibility? Prod. Oper. Manag. 2012, 21, 1042-1059. [CrossRef]

49. Sim, J.E.; Kim, B. Commitment to environmental and climate change sustainability under competition. Sustainability 2019, 11, 2089. [CrossRef]

50. Kojoyan, S. The Economics of Sustainable Coffee Production. Available online: https://www.triplepundit. com/story/2014/economics-sustainable-coffee-production/39121/ (accessed on 1 August 2019).

51. Zailani, S.; Govindan, K.; Iranmanesh, M.; Shaharudin, M.R.; Sia Chong, Y. Green innovation adoption in automotive supply chain: The Malaysian case. J. Clean Prod. 2015, 108, 1115-1122. [CrossRef]

52. Chen, Y.-S. The driver of green innovation and green image-Green core competence. J. Bus. Ethics 2007, 81, 531-543. [CrossRef]

53. Raz, G.; Druehl, C.T.; Blass, V. Design for the environment: Life-cycle approach using a newsvendor model. Prod. Oper. Manag. 2013, 22, 940-957. [CrossRef]

54. Krass, D.; Nedorezov, T.; Ovchinnikov, A. Environmental taxes and the choice of green technology. Prod. Oper. Manag. 2013, 22, 1035-1055. [CrossRef]

55. Lv, B.; Qi, X. Research on partner combination selection of the supply chain collaborative product innovation based on product innovative resources. Comput. Ind. Eng. 2019, 128, 245-253. [CrossRef]

56. Cachon, G.P. Supply Chain Coordination with Contracts. In The Handbooks of Operations Research and Management Science: Supply Chain Management; Graves, S., de Kok, T., Eds.; Elsevier North-Holland: Amsterdam, The Netherlands, 2003; pp. 227-339.

57. Hu, B.; Xu, D.; Meng, C. Inconsistency of a retailer's optimal policies and channel performance under revenue sharing contracts. Int. J. Prod. Econ. 2017, 183, 53-65. [CrossRef]

(C) 2019 by the authors. Licensee MDPI, Basel, Switzerland. This article is an open access article distributed under the terms and conditions of the Creative Commons Attribution (CC BY) license (http://creativecommons.org/licenses/by/4.0/). 